\title{
O conceito de comunidade: problematizações a partir da psicologia comunitária
}

\section{The concept of community: problematizations from community psychology}

\section{El concepto de comunidad: problematizaciones de la psicología comunitaria}

\section{Lurdes Perez Oberg*}

Universidade Federal Fluminense - UFF, Niterói, Rio de Janeiro, Brasil

\begin{abstract}
RESUMO
O objetivo deste artigo é propor uma discussão sobre o conceito de comunidade, a partir de uma perspectiva histórica e política. Entende-se, ainda, que a psicologia comunitária traz este debate na década de 70 , favorecendo atividades científicas e práticas profissionais em contextos considerados como periféricos. Num primeiro momento, iremos apresentar comunidade em sua dimensão histórica, citando autores da sociologia clássica. Num segundo momento, discutiremos sobre a inserção deste conceito na psicologia social comunitária e, finalmente, problematizaremos as formas de comunidade presentes na contemporaneidade, tomando Bauman e Castells como referências. Espera-se, ainda, contribuir para uma visão não uniformizadora dos laços sociais e que se possa, com este estudo, alcançar práticas profissionais que considerem na relação subjetividade e objetividade, individualidade e coletividade, um trilhar para uma perspectiva ético-política na Psicologia.
\end{abstract}

Palavras-chave: comunidade, psicologia comunitária, práticas profissionais.

\begin{abstract}
The objective of this paper is to propose a discussion of the concept of community, from a historical and political perspective. It is understood also that community psychology brings this debate in the $70 \mathrm{~s}$, promoting scientific and professional practice activities in contexts considered as peripheral. Initially, we will present community in its historical dimension, citing authors of classical sociology. Secondly, we will discuss about the inclusion of this concept in community social psychology and finally, we question forms of community present in contemporary times, taking Bauman and Castells, as references. It is expected to contribute to a non-unifying vision of social ties and that this study achieve professional practices to consider in relation subjectivity and objectivity, individuality and collectivity, one walk for an ethical-political perspective in psychology.
\end{abstract}

Keyboards: community, community psychology, professional practices. 


\begin{abstract}
RESUMEN
El objetivo de este trabajo es proponer un debate sobre el concepto de comunidad, desde una perspectiva histórica y política. Se entiende también que la psicología comunitaria trae este debate en los años 70, la promoción de actividades prácticas científicas y profesionales en contextos considerados como periféricos. Inicialmente, presentaremos la comunidad en su dimensión histórica, citando autores de la sociología clásica. En segundo lugar, vamos a discutir acerca de la inclusión de este concepto en la psícología social comunitaria y, por último, que cuestionar formas de comunidad presente en la época contemporánea, teniendo Bauman y Castells, como referencias. Se espera que contribuya a una visión no unificador de los vínculos sociales y que con en este estudio, lograr prácticas profesionales a tener en cuenta en relación con la subjetividad y la objetividad, la individualidad y la colectividad, un paseo por una perspectiva ético-política en la psicología.
\end{abstract}

Palabras clave: la comunidad, la psicología comunitaria, las prácticas profesionales.

\title{
1 I ntrodução
}

A psicologia social comunitária, com seu potencial de transformação e reveladora das tensões da Psicologia, traz em seu bojo, na década de 1970, a discussão do conceito de comunidade. Partimos, neste artigo, da leitura de sua dimensão histórica e consideramos que não encontramos consenso quanto ao seu significado. $O$ entendimento sobre o viver em comunidade implica testemunhar a cultura em que vivemos e problematizar as diversas formas como os homens estão construindo os seus vínculos.

Como explicitado por Sawaia (1999, p. 50), não existe a intenção de apresentar comunidade como um "conceito plenamente elaborado e fechado, o que significaria retirar o caráter sócio-político e utópico que a caracteriza, transformando-a em conceito vazio e abstrato".

$O$ interesse de escrever este artigo surge por desejarmos instigar uma discussão neste campo do conhecimento e na literatura existente, provocando a troca de ideias nas nossas práticas profissionais. Tomamos como referência neste estudo o exposto por Freitas (2014) no tocante às reflexões sobre tais práticas. A autora sugere que estas devem permitir a convivência das diversidades e diferenças, enfrentando os preconceitos $e$ as inequidades experimentados na vida cotidiana. Dessa forma, a autora menciona o compromisso com a construção de relações e redes de convivência mais solidárias e humanas, desafio este de que podemos nos apropriar no discurso e em nossos fazeres.

Concebemos que o escopo da psicologia social comunitária na atualidade, além de promover um debate coletivo de resistência na cultura contemporânea (Oberg, 2008), ultrapassa o fazer do psicólogo na comunidade e traz contribuições para o diálogo 
interdisciplinar nas políticas públicas. Lembramos que, no seu corpo teórico-metodológico, a psicologia social comunitária se constitui como um campo de conhecimento sustentado em disciplinas como a sociologia, a antropologia, a história (Costa Araújo, 1999; Domingues \& Franco, 2014), o que indica o seu potencial de interlocução com as ciências humanas e sociais.

Ao adentrar no percurso histórico das práticas comunitárias na realidade brasileira, constatamos a mudança do paradigma assistencialista para o paradigma de direitos, construída desde a década de 70. Há que se destacar, neste período, uma significativa participação política dos psicólogos nos movimentos populares e nas atividades e práticas deselitizantes contrárias ao regime militar, até alcançarmos a Constituição de 1988 (Freitas, 1999; Nascimento, 2001).

Sabemos que existem possibilidades de avanços e retrocessos nesta trajetória e o confronto destes paradigmas é um campo de disputas que enfrentamos em nossas práticas atuais (Ansara \& Dantas, 2010; Oliveira, 2014).

Esta mudança de foco, a partir do entrosamento com outras disciplinas, convida-nos a construir novas formas de interpretação e de atuação no mundo. Surge o desafio para que se produzam conhecimentos e metodologias de ação que orientem a prática na política pública, (Afonso, Vieira-Silva, Abade, Abrantes \& Fadul, 2012). I mportante considerar as condições teóricas e metodológicas que sustentam as práticas realizadas, assim como as formas de relações estabelecidas com as políticas públicas e que podem contribuir para o fortalecimento desses trabalhos (Freitas, 2014).

Nesta direção, a psicologia social comunitária, a partir da década de 70, ressalta atividades científicas em contextos considerados como periferias. Gavroglu (2008, p. 158) fala de "novos questionamentos e novos pontos sensíveis, muito mais próximos da visão de ciência que vem de baixo, parecem estar sendo progressivamente aplicados ao estudo das colônias e também _ por que não _ às periferias europeias".

Em outro estudo, investigamos o viver em comunidade, a partir da ótica de mulheres moradoras de uma comunidade pobre, na zonaoeste do Rio de Janeiro. Levantamos temas como o individualismo, a valorização de interesses coletivos, as amizades, a segurança e a liberdade, a vida privada, o espaço público, o papel do Estado, o significado da sociedade, a vida em outras comunidades e a comunidade vivida na infância (Oberg, 2008). Verificamos que tais atividades incentivam a interlocução e o confronto de vozes das moradoras da comunidade com o posicionamento do pesquisador a partir, inclusive, de autores estudados. O reconhecimento das tradições locais e de formas específicas de resistências favorece a escuta dos moradores de comunidades populares, como nos ensina 
Gavroglu e Patinotis (2008). Convém, ainda, destacar que "comunidade popular é hoje um território de ebulição de constante forças micropolíticas" (Rocha \& Kastrup, 2008, p. 101-102).

No presente artigo iremos, em um primeiro momento, discutir 0 conceito de comunidade, estabelecendo suas conexões com o contexto histórico, quando faremos referência a autores da sociologia clássica. Num segundo momento, refletiremos sobre a inserção deste conceito na psicologia social comunitária, a partir da década de 70 . Avançamos de uma perspectiva orientada pelo condutivismo e pelo cognitivismo, bem como pelo método experimental, com o objetivo de buscar a integração de indivíduos e grupos ao contexto social, para outra que valoriza a luta dos psicólogos contra a exclusão social, presente na sociedade brasileira e que reconhece a importância da crítica aos estudos norte-americanos, estudos, estes, que não consideram o ser humano como agente de mudança e sujeito da história (Sawaia, 1999; Lane, 1992). Teremos sempre em mente a dimensão política do termo comunidade, a compreensão de que o individualismo é um entrave para o fortalecimento dos laços sociais e que os mesmos são conflitivos numa sociedade capitalista.

Por fim, debateremos a relação comunidade e contemporaneidade. Entendemos que comunidade nos remete a uma "sensação de aconchego", "paraíso perdido", porém o contexto vigente é de intensa individualização e desintegração dos laços humanos dos nossos tempos, sem alicerces sociais e relacionais firmes e previsíveis, prevalecendo uma forma de "comunidade estética" e com laços superficiais (Bauman, 2003). Com Castells (2003, 2013), consideraremos as "comunidades instantâneas", formadas através dos movimentos sociais de rede, sinalizando o surgimento de espaços híbridos, pois são construídos entre as redes sociais da internet e o espaço urbano ocupado por estas redes de indignação.

O título deste artigo mostra uma recusa deste campo a posições que não considerem a heterogeneidade e as diferenças, presentes nos discursos dos especialismos e que reforçam modos de existência fixos e imutáveis. Valorizamos as contribuições dos autores da psicologia social comunitária, mas nos arriscamos a pensar em outros possíveis e, assim, fazemos valer uma radicalização da democracia nesta perspectiva, ressaltando o conhecimento histórico a respeito dos diferentes grupos e comunidades, relacionando-os às dimensões locais, regionais e globais (Freitas, 2014).

Pretendemos, com este trabalho, valorizar um ponto de vista processual em contraposição a uma perspectiva naturalizante em que não se aceita a dicotomia centro-periferia. Compreendemos que, ao superarmos esta dicotomia, estamos recusando uma visão hierárquica e hegemônica em nossas pesquisas e posições acadêmicas em relação aos referenciais geográficos, culturais, políticos e econômicos dos grandes centros (Gavroglu \& Patinotis, 
2008). Assim, com a intenção de promover estratégias de apropriação de saberes vistos como marginais, acolhemos horizontes em que a relação centro e periferia possa ser tomada a partir de um ponto de vista histórico e político.

\section{0 conceito de comunidade e a história}

Sabemos que, com a transformação das sociedades industriais, a comunidade aparece como inimiga do progresso e do desenvolvimento econômico, sempre em oposição à sociedade. Entendemos, também, as grandes provocações ao tentarmos uma reflexão sobre este conceito. $\mathrm{Na}$ atualidade, já avançamos, consideravelmente, nesta análise, ao desafiarmos a homogeneização, a estabilidade, a harmonia e a individualização dos laços sociais (Bauman, 2003; Sawaia, 1999; Zamora, 1999, 2004).

Enfatizamos, todavia, a necessidade de compreensão da relevância cultural da ciência para a sociedade em múltiplos contextos e diferentes períodos históricos (Gavroglu, 2008).

São bem conhecidas algumas das concepções clássicas de comunidade, referenciadas a Ferdinnand Tönnies (1955), Max Weber (1973) e Georg Simmel (1979), fundadores da sociologia alemã, os primeiros teóricos ocidentais a se debruçarem sobre o conceito de comunidade, sendo Tönnies visto como o "pai" deste conceito. Tönnies (1955) inicia, assim, o debate distinguindo a Gemeinschaft (comunidade) da Gesellschaft (sociedade).

A Gemeinschaft (comunidade) é uma associação que ocorre na linha do ser, apresenta uma participação profunda dos membros do grupo, e as relações primárias são colocadas em comum, como o próprio ser, a própria vida, o conhecimento mútuo, a amizade, os sentimentos, a união, a proximidade, enquanto a Gesellschaft (sociedade) é uma associação que ocorre na linha do haver, os membros do grupo colocam em comum algo que possuem, como o dinheiro, a capacidade técnica e os interesses racionais. Esta impõe o anonimato (Oberg, 2008).

Além de considerar as contraposições entre comunidade e sociedade, Tönnies (1955) sustenta a naturalização de uma essência comunitária universal, estando a comunidade relacionada à vida em grupos coesos e unidos por interesses comuns. Acompanhamos Sawaia (1999), para quem esta antítese entre comunidade e sociedade, um contraste entre valores comunitários e não comunitários, é a polêmica exposta pela sociologia, ciência emergente no início do século XIX, possibilitando "comunidade" tornar-se central no pensamento social neste período histórico. Ainda, Palácios (2001, p.1) confirma que a "ideia ou conceito de comunidade, tão central na 
sociologia clássica, é uma invenção da Modernidade", criada para se referir principalmente ao modo de vida feudal.

No Iluminismo, ocorre um movimento de hostilidade intelectual à comunidade, oriundo do desejo de destruir a ordem feudal injusta, o que é reforçado por duas revoluções, a francesa e a industrial. Nesse mesmo período, porém, emerge um pensamento conservador, de resgate da comunidade como padrão de boa sociedade. Comunidade, então, torna-se o centro do debate da modernidade nascente, ora vista como conservadora e contrária ao progresso, ora valorizada por aqueles que desprezavam a modernização. (Sawaia, 1999). Assim, esta autora afirma que Tönnies, no início do século XIX,

(...) criou uma estrutura tipológica da ideia de comunidade, onde sistematizou a noção de comunidade esboçada no início do referido século, tanto pelos conservadores como pelos revolucionários, recolocando-a como critério de oposição entre modernização e tradição, apesar de afirmar que comunidade faz parte da sociedade (Sawaia, 1999, p. 39,40).

Para outro autor contemporâneo de Tönnies, Weber (1973), comunidade já se torna um conceito amplo apoiado em fundamentos afetivos, emocionais e tradicionais. Este autor explica que a comunidade é uma relação social em que a atitude na ação social, em termo médio ou no "tipo ideal", inspira-se em um sentido de solidariedade e como fruto do sentimento subjetivo (afetivo ou tradicional) dos participantes na constituição de um todo.

O sociólogo Georg Simmel, por sua vez, denuncia a objetivação crescente da cultura moderna e a consequente impessoalidade das relações, a ponto de anular a totalidade da subjetividade humana, favorecendo o surgimento de um tipo de comunidade, que ele denominou sociedade secreta, criada para separar o indivíduo alienado da sociedade impessoal, podendo tornar-se um fator de dissociação mais do que de socialização (Sawaia, 1999).

Podemos afirmar, a partir de Tönnies, Weber e Simmel, que a comunidade seria o lugar do afeto, das relações primárias, da tradição, da partilha de interesse e de território comum, ao passo que a sociedade seria seu contrário, marcada pela racionalidade, pela modernidade, pelas relações secundárias com pouco contato face a face e com fins econômicos (Oberg, 2008).

Soares (2001) considera que, através desta visão romantizada, está presente uma visão de comunidade como arquétipo de relação ideal, formada em tempos passados e que teria sido perdida pelo homem. Comunidade indicaria, pois, um lugar do bem, onde todos seriam naturalmente bons e poderiam construir relações estáveis e harmônicas. 
Rocha \& Kastrup (2008) argumentam que os ensaios de definição do conceito de comunidade na psicologia, mesmo sendo variados e não precisos, são "construídos a partir de uma compreensão sociológica original, que relacionou comunidade e sociedade como categorias esquadrinhadas por uma regulação social e disciplinar, compartimentada" (Rocha \& Kastrup, 2008, p.101). Por este motivo, torna-se necessário revermos estes autores da sociologia clássica e procurar que o conceito de comunidade seja verificado em contexto, a partir dos sentidos produzidos e das práticas abrigadas. Podemos considerar comunidade como um não-lugar, como utopia, ou lugar de convivência e alteridade (Scarparo \& Guareschi, 2007).

Desta forma, desde a década de 70, a psicologia social comunitária busca desenvolver uma concepção de comunidade que sobrepuje estas posições sociológicas clássicas dicotômicas e naturalizantes. Assumimos, assim, o compromisso de desnaturalizarmos práticas normatizadoras e que apresentam um cotidiano acrítico e a-histórico. Anterior a esse período, na década de 60 , sabe-se que os psicólogos buscaram uma inserção em locais menos privilegiados, visando uma deselitização da profissão. Entretanto, a ditadura militar que se implanta em março de 1964 promove um regime de terror cultural e político na sociedade brasileira (Freitas, 1999). Os efeitos deste contexto opressor se evidenciam nas práticas psicológicas e numa formação profissional sustentada por abordagens individualistas, descontextualizadas e regidas por uma visão de sujeito abstrato. $\mathrm{Na}$ psicologia, tais posições confirmam uma visão de naturalização das ações de violência e repressão daquele cenário (Scarparo \& Guareschi, 2007).

Para a crítica desta visão, torna-se imprescindível a compreensão fatalista da existência humana, exposta pelo psicólogo social Ignácio Martin Baró. Para ele (2017), atribui-se ao povo latino-americano um destino inevitável e a vida humana, nesta percepção, está predeterminada, reforçando comportamentos de conformismo, submissão e resignação.

O fatalismo é um esquema ideológico que parte da estrutura social e é interiorizado, garantindo a reprodução e a manutenção das relações sociais vigentes na ordem hegemônica. O processo de ruptura do fatalismo não requer apenas a mudança individual ou a transformação das condições sociais: é dialético, no tocante a uma mudança da relação entre o indivíduo e a sociedade (Ansara \& Dantas, 2010).

Nesta direção, a introdução do conceito de comunidade na psicologia social pode ser tomada como um aspecto epistemológico importante, pois assume a opção por uma teoria crítica que interpreta o mundo com a finalidade de transformá-lo (Sawaia, 1999).

Avançaremos nesta discussão nas décadas de 1970 e 1980, momento fecundo para a problematização do conceito de comunidade. 


\section{A inserção do conceito de comunidade na psicologia social comunitária}

A partir do tópico anterior, podemos considerar que as teorias são construções sócio-históricas que expressam visões de homem e de mundo que Ihes são próprias. Sawaia (1999) nos mostra que o conceito de comunidade é um conceito ausente na história das ideias psicológicas e apenas nos anos 70 surgiu como referencial de análise na psicologia social comunitária.

Já consideramos em outro estudo (Oberg, 2015), as décadas de 1970 e 1980 como um período de significativas rupturas socioculturais, políticas e filosóficas. Dizíamos então:

Os efeitos dos acontecimentos de maio de 68 na França, os movimentos da psiquiatria italiana e francesa a favor de novas práticas de saúde mental, os movimentos latino-americanos que contestavam a ditadura militar, a crítica que se faz à psicologia social norte-americana e a psicologia dos pequenos grupos dentre outros, possibilitam uma psicologia voltada para trabalhos comunitários e que atendam a nossa realidade brasileira (Oberg, 2015, p.116).

Não se encontram referências explícitas sobre comunidade nas obras de psicologia social até os anos 70, quando foi introduzida no corpo teórico da psicologia comunitária, por meio das primeiras publicações numa vertente crítica nesse campo. Na psicologia social, ramo da psicologia institucionalizado no início do século $X X$, o conceito de comunidade aparece no lugar de grupo e de interação social. Com nítida influência da psicologia social norte-americana, os estudos sobre fenômenos coletivos, decorrentes dos problemas sociais oriundos da Segunda Guerra Mundial, tinham como objetivo ajustar e adaptar comportamentos individuais ao contexto social (Sawaia, 1999).

Este enfoque adaptativo, juntamente com a valorização da clínica tradicional, curativa, individualizante e de práticas grupais isoladas de seu contexto sócio-histórico, foi gradativamente sendo superado por considerações sobre a psicologia comunitária, dando prioridade para as maiorias populares, com ênfase nos processos grupais e coletivos, e apresentando uma visão histórica e social mais ampla, com compromisso ético-político. Nesta perspectiva, o fenômeno psicológico é entendido como integrado a aspectos sociais, psicológicos e biológicos; uma abordagem interdisciplinar e interparadigmática. Isto permite o surgimento de trabalhos em equipes interprofissionais horizontalizadas (Andery, 1992; Freitas, 1999; Garcia, Morgado \& Vasconcelos, 2011). 
No final dos anos 70, ocorre no Brasil um expressivo fortalecimento dos movimentos sociais, destacando-se neles três matrizes discursivas: a presença da teologia da libertação, a partir das comunidades eclesiais de base; o marxismo, presente nas associações de bairro através da Educação Popular de Paulo Freire; e a emergência do novo sindicalismo que expressa lutas travadas no cotidiano. Assim, quando a psicologia vai para a comunidade, há um encontro com tais práticas e se visualiza uma intervenção destes movimentos nas Ciências Humanas e Sociais, emergindo a ação de profissionais engajados, entre eles o psicólogo (Andery, 1992; Nascimento, 2001).

Há o rompimento com a noção de comunidade passiva e estática na década de 1970. O modelo latino-americano, surgido neste período, com base em práticas de intervenção comunitária, tem, no materialismo dialético, os fundamentos para sua atuação. Os conceitos de ideologia, consciência de classe, hegemonia, intelectual orgânico, a partir dos referenciais de Marx e Gramsci, estão inseridos neste modelo que sustenta a transformação social e os movimentos sociais (Nascimento, 2001; Scarparo \& Guareschi, 2007).

Partimos, pois, de um consenso possível que prioriza uma perspectiva ético-política na psicologia, ampliando os espaços de participação social, de desenvolvimento de potencialidades e de valorização dos saberes locais, seja no próprio serviço, seja na própria localidade, considerando, ainda, a relevância da interdisciplinaridade e da intersetorialidade. A posição tecnicista, porém, ainda é predominante em diversos contextos, mostrando que continuam existindo práticas padronizadas que colocam o profissional numa posição dominante na relação com o outro (Freitas, 1996; Garcia, Morgado \& Vasconcelos, 2011, Góis, 2005).

Desta forma, o rompimento da noção de comunidade passiva e estática na década de 1970 é crucial neste momento. Quais as contribuições que podemos apresentar para ampliarmos a visão sobre as comunidades populares e periferias com suas forças micropolíticas?

Rocha \& Kastrup (2008) consideram uma visão de comunidade sustentada por seres singulares e seus encontros em oposição à outra, feita do sonho fusional, da homogeneização, da fragmentação. A singularidade expressa na idéia de comum ocorre na formação de um espaço cooperativo onde as peculiaridades possam se encontrar e, juntas, apostar na construção de um território, processo que não acontece pela enlace de individualidades.

A constituição do comum é uma ideia que tem sido utilizada para pensar o desejo, o processo de formação de comunidades e de redes associativas de produção comum. A constituição do comum pode romper divisões como centro-periferia, comunidade e sociedade, psicologia na comunidade e psicologia da comunidade e criar novos 
modos de existência e de estarmos juntos numa sociedade marcada por um intenso processo de individualização.

Percorrendo uma trajetória analisada por Freitas (1999), pode-se afirmar que a psicologia na comunidade (décadas de 60 e 70) foi assim identificada no momento em que a psicologia vivia uma crise em relação aos modelos importados, distantes da nossa realidade. A psicologia precisava ser desenvolvida na comunidade e não apenas nos consultórios e nas escolas. O objetivo era deselitizar a profissão e deixá-la mais próxima às condições de vida da população. A partir de 1985, utiliza-se a expressão "psicologia da comunidade" vinculada às questões da saúde, ao movimento de saúde. Observam-se atuações de psicólogos em instituições geralmente públicas, como postos de saúde, setores ligados às instituições penais, órgãos de família etc. Espera-se, nestes momentos, que o psicólogo tenha um papel de trabalhador social dentro dos movimentos de saúde. Estas atuações tiveram uma influência da Análise Institucional, do Movimento Instituinte e das intervenções psicossociológicas, com instrumentais das vertentes clínicas e educacionais.

Freitas (1999, p.72) analisa que "durante o passar desses anos, o emprego das expressões foram se misturando e se confundindo, especialmente em termos na e da, como que sinonímia".

Interessante questionarmos se, na atualidade brasileira, a "psicologia na comunidade" e a "psicologia da comunidade" são noções dicotômicas, pois, os retrocessos que vivemos hoje acentuam um distanciamento entre as práticas comunitárias e as condições objetivas e subjetivas de vida dos moradores das comunidades, as suas singularidades e as possibilidades de constituição do comum.

A problematização do conceito de comunidade na psicologia social comunitária, no instante que rompe o viés sociológico disciplinar, uno e homogêneo, pode propiciar uma ruptura na dicotomia centroperiferia, "se assumirmos uma psicologia que se faz política ao promover deslocamentos, inventar novos problemas, construir entre os sujeitos implicações que apontem para outros mundos possíveis, dada a produção de desejo imanente ao coletivo: desejo de transformação não apenas das condições físicas do ambiente, geralmente perversas e indignas em vários aspectos, mas também desejo de criar novas normas de (con)viver, formas mais abertas, artísticas" (Rocha \& Kastrup, 2008, p.100).

Na luta contra a exclusão social na realidade brasileira, sabemos que afetividade é um viés desestabilizador da exclusão social. Como explicado por Sawaia (1999a), reconhecemos os aspectos sociais, históricos, políticos e econômicos que envolvem este tema. Porém, a inserção da afetividade no rol dos itens citados pode contribuir para outro olhar na dinâmica social centro-periferia.

No tópico a seguir, "Comunidade e Contemporaneidade", prosseguimos refletindo sobre o conceito de comunidade, porém nos 
interessam os desafios nas práticas comunitárias, diante de uma individualização crescente existente numa sociedade globalizada e as possibilidades que podem emergir para o não silenciamento das maiorias populares.

\section{Comunidade e Contemporaneidade}

Como pesquisadores no campo da psicologia social comunitária, entendemos ser este debate relevante para avançarmos em nossos estudos e fazeres na área. A inserção do conceito de comunidade neste campo pode ser um analisador de questões sociais, políticas, econômicas do contexto social e de transformações na própria psicologia.

Como já vimos, a aproximação da psicologia com a comunidade no final dos anos 1970, acontece num contexto da emergência de práticas transformadoras (presença da Teologia da Libertação, da teoria de Educação de Paulo Freire, etc.) junto com a participação dos movimentos sociais.

Assim, além de superarmos uma psicologia a-histórica e individualizante, este conceito na psicologia social comunitária é uma referência para lutarmos por um projeto coletivo de resistência no debate contemporâneo. Para isto, foi importante investir numa desconstrução de ideias naturalizadoras sobre comunidade, reconhecendo a dialética individualidade e coletividade (Sawaia, 1999).

Sabemos que a gênese teórica e social é inseparável na produção de conhecimento e, no presente trabalho, levamos isto em consideração. Portanto, como já visto, na virada do séc. XIX para o século XX, o filósofo alemão Ferdinand Tönnies (1955) aponta a existência de uma essência comunitária universal e considera o conceito de comunidade em oposição à sociedade. Estamos, assim, num tempo histórico no qual experenciamos os efeitos de uma posição conservadora e dicotômica. A investigação desta concepção na atualidade é inseparável das tensões do contexto do capitalismo globalizado, indicando uma polissemia em torno do seu significado.

Prosseguimos com a argumentação em torno deste conceito na contemporaneidade.

Estamos assumindo uma posição em que rechaçamos relatos históricos hegemônicos e estamos abertos a uma epistemologia ativa das periferias, de forma similar a uma interação dinâmica entre as metrópoles e as periferias na troca de conhecimento científico (Gavroglu \& Patinotis, 2008).

Para discutir a contemporaneidade, vamos nos embasar em dois autores: Zymunt Bauman (2003) e Manuel Castells (2003, 2013). Bauman, pela sua capacidade de analisar a dimensão histórica desse 
conceito e problematizá-lo em nossos dias. Castells (2013), por apresentar, através de uma leitura dos movimentos sociais em rede, outra possibilidade de discutirmos as redes de indignação como uma forma de comunidade dos nossos tempos: as comunidades instantâneas de prática transformadora, geradas como um espaço híbrido entre as redes sociais da internet e o espaço urbano ocupado. Inserimos Bauman e Castells no rol de autores que criam espaços para refletirmos sobre as resistências e sobre novos modos de apropriação do conhecimento numa sociedade globalizada.

O sociólogo Zymunt Bauman (2003) cita hipóteses que formam o "fundamento epistemológico" da experiência de comunidade, como uma história social e individual mais duradoura, mais segura e confiável do que o tempo de uma vida individual. Observa-se, segundo este autor, 0 enfraquecimento da experiência de comunidade no capitalismo, constatando-se o afrouxamento sucessivo dos laços nacionais, regionais, comunitários, de vizinhança e de família.

Sabemos que o "viver em comunidade" se transforma com o advento da informação. Esse autor analisa que a comunicação entre os de dentro da comunidade e o mundo exterior se intensifica a partir deste momento e passa a ter mais peso que as trocas mútuas internas (Bauman, 2003).

Importante entender, segundo Bauman, que, embora associemos a palavra "comunidade" a uma coisa boa, "sensação de aconchego", paraíso perdido ou esperado, a comunidade imaginada, sonhada apresenta diferenças da "comunidade realmente existente". Esta exige rigorosa obediência em troca dos serviços que presta ou promete prestar:

Você quer segurança? Abra mão de sua liberdade, ou pelo menos de boa parte dela. Você quer poder confiar? Não confie em ninguém de fora da comunidade. Você quer entendimento mútuo? Não fale com estranhos, ... Você quer essa sensação aconchegante de lar? Ponha alarmes em sua porta e câmeras de tevê no acesso. Você quer proteção? .... Não chegue perto da janela, e jamais a abra. O nó da questão é que se você seguir esse conselho e mantiver as janelas fechadas, 0 ambiente logo ficará abafado e, no limite, opressivo (Bauman, 2003, p. 9, 10).

Bauman descreve a difícil equação entre segurança e liberdade e, portanto, entre comunidade e individualidade. "Não seremos humanos sem segurança ou liberdade, mas não teremos as duas ao mesmo tempo" (Bauman, 2003, p.11).

Desta forma, esse autor descreve a ambivalência do individualismo moderno, vetor da emancipação dos indivíduos, de autonomia, mas 
de intensa individualização, rotina coercitiva e desintegração dos laços humanos (Bauman, 2003).

Na sociedade globalizada e de risco, expressão de Ulrich Beck não há certeza, controle e segurança. "De fato, não há estruturas firmes, nem origens de classe que não possam ser deixadas para trás, nem passado que não possa ser jogado fora" (como citado em Bauman, 2003, p.58).

No mundo flexível dos negócios e da indústria cultural, não há lugar para realidades obstinadas e duras como a pobreza, o desprezo e a humilhação que representam a incapacidade de participar do jogo do consumo. Elimina-se, neste contexto, a comunidade de compartilhamento do bem-estar coletivamente alcançado e, ainda, a responsabilidade dos mais favorecidos de dar apoio aos mais pobres (Bauman, 2003).

Nesse instante, Bauman diferencia a elite global da "comunidade", aquela dos fracos e despossuídos. "A necessidade da comunidade estética gerada pela ocupação com a identidade é o campo preferencial que alimenta a indústria de entretenimento" (Bauman, 2003, p.63). Esta é orientada pela sedução. Nas figuras de ídolos, por exemplo, apela-se à experiência de comunidade, porém, sem a chance do encontro com a comunidade real, obtém-se a satisfação de fazer parte dela, sem o incômodo do compromisso. Este autor menciona a formação de comunidades instantâneas em torno dos líderes: estas encontram-se prontas para o consumo imediato e também são descartáveis depois de usadas. "Uma coisa que a comunidade estética definitivamente não faz é tecer entre os seus membros uma rede de responsabilidades éticas e, portanto, de compromissos a longo prazo" (Bauman, 2003, p.67). Na breve vida da comunidade estética, esta apresenta laços pouco duradouros, superficiais e com "vínculos sem consequências" (Bauman, 2003).

Assim, neste mundo fluido e imprevisível de desregulamentação, flexibilidade e incerteza, "cada um de nós sofre a ansiedade por conta própria, como problema privado, como resultado de falhas pessoais e como desafio ao nosso savoir fair e à nossa agilidade" (Bauman, 2003, p.129).

Neste cenário globalizado, constatado por Bauman, se vier a existir uma comunidade no mundo dos indivíduos, só poderá ser uma comunidade tecida em conjunto, a partir do compartilhamento e do cuidado mútuo. O autor alerta para uma comunidade de interesse e responsabilidade em relação aos direitos de sermos iguais e lutarmos em defesa destes direitos (Bauman, 2003).

Para caminharmos nesta direção, conforme aprendemos com Bauman (2003), devemos prezar pelo reconhecimento da diversidade, acolhendo que muitos dos desafios que enfrentamos não poderão ser vividos individualmente. A simplificação, a mesmice, o transitar 
unicamente na superfície somente sinalizam um mínimo de diversidade e isto não garante a construção coletiva.

Castells (2003), por sua vez, analisa a formação de comunidades virtuais, como a "culminação de um processo histórico de desvinculação entre localidade e sociabilidade na formação da comunidade: novos padrões seletivos, de relações sociais substituem as formas de interação humana territorialmente limitadas" (2003, p.98). Porém, isto não significa que a sociabilidade baseada em lugar não exista mais ou que as sociedades evoluam no sentido uniforme das relações sociais (Castells, 2003). "O mundo social da Internet é tão diverso e contraditório quanto a própria sociedade" (Castells, 2003, p.48).

O autor enfatiza, assim, o deslocamento do conceito de comunidade para o de rede como a forma central de organizar a interação. Acrescenta, ainda, que, para compreendermos novas formas de interação social na era da Internet, devemos propor uma redefinição de comunidade que realce menos o seu componente cultural e destaque mais o seu papel de apoio a indivíduos e famílias. "Comunidades são redes de laços interpessoais que proporcionam sociabilidade, apoio, informação, um senso de integração e identidade social" (Castells, 2003, p.106).

Castells (2013) discute os movimentos sociais em rede, a sua formação, dinâmica, valores e perspectivas de transformações sociais. Para esse autor, na sociedade em rede o poder é multidimensional e se organiza em torno de redes programadas em cada domínio da atividade humana. As redes de poder influenciam a mente humana, mediante redes de multimídia de comunicação de massa, sendo formas decisivas de construção de poder.

As relações de poder estão inseridas nas instituições da sociedade, particularmente naquelas vinculadas ao Estado. Estas são constitutivas da sociedade e os que detêm o poder constroem as instituições segundo seus próprios princípios e interesses. Porém, como as sociedades são contraditórias e conflitivas, onde há poder, encontramos também contrapoder, formas de resistências aos poderes instituídos (Castells, 2013).

Verificamos que o contrapoder exercido pelos movimentos sociais se manifesta numa tentativa deliberada de alterar as relações de poder. Ficam livres do controle dos que detêm o poder institucional e criam, mediante um processo de comunicação, redes autônomas e horizontais. Os movimentos sociais reprogramam a rede em torno de outros interesses e valores, ao mesmo tempo em que vão se alterando as redes de resistência e de mudança social (Castells, 2013).

Ao exercerem o contrapoder, os movimentos sociais constroem comunidades livres no espaço urbano. Já que o espaço público institucional, o espaço constitucionalmente designado para a 
deliberação, está ocupado pelo interesse das elites dominantes e suas redes, os movimentos sociais precisam abrir um novo espaço público que não se limite à internet, mas tenha visibilidade nos lugares da vida social, ocupando o espaço urbano e os prédios simbólicos (Castells, 2013).

Castells (2013) segue sinalizando que os espaços ocupados pelos movimentos sociais têm desempenhado papel importante na história da mudança social e na prática contemporânea, pois criam uma comunidade que se baseia na proximidade. A proximidade é um mecanismo psicológico essencial para vencer o medo e superá-lo: é o ponto crucial para os atores sociais estarem inseridos num movimento social. O medo é visto por Castells como uma emoção paralisante, decorrente da força dos poderes constituídos que se reproduzem, causando intimidação e violência, presentes de forma disfarçada ou institucionalmente aplicada.

Além disto, os espaços ocupados são carregados do poder simbólico, pois são geralmente áreas de propriedade do Estado ou de instituições financeiras, gerando uma intensa desconfiança nas instituições políticas que administram a sociedade. A deterioração das condições materiais de vida e a crise de legitimidade dos governantes promove a ação coletiva em direção à transformação social.

Constatamos, com a ajuda de Castells (2013), que estes atores sociais criam uma comunidade livre num espaço simbólico, público e político. O espaço público destes movimentos sociais é construído como um espaço híbrido entre as redes sociais da internet e o espaço urbano ocupado: esta conexão do ciberespaço com o espaço urbano constitui, tecnológica e culturalmente, "comunidades instantâneas" de prática transformadora. Espaço em rede, situado entre o espaços digital e o urbano, é o espaço da comunicação autônoma, essência dos movimentos sociais, pois permite que os movimentos se relacionem com a sociedade em geral, para além do controle dos detentores do poder da comunicação.

Podemos reiterar, acompanhando Castells (2003), que as comunidades vituais trabalham com base em duas características fundamentais comuns: o valor da comunicação livre e horizontal e o da formação autônoma de redes. "Isto é, a possibilidade dada a qualquer pessoa de encontrar sua própria destinação na Net, e, não a encontrando, de criar e divulgar sua própria informação, induzindo, assim, na formação de uma rede" (Castells, 2003, p. 48-49).

Neste aflorar dos espaços dos fluxos destas comunidades instantâneas, locais e globais (Castells, 2013), reconhecemos uma estrutura descentralizada avessa às instituições hierárquicas, sem fronteiras definidas, sem uma liderança formal, movidas por sentimentos de indignação diante das grandes desigualdades sociais que são efeitos do contexto globalizado. 
Castells não se retira do debate sobre a divisão digital e os efeitos cumulativos destes mecanismos de exclusão que separam pessoas por todo o planeta. Talvez seja tarefa para os movimentos sociais em rede agirem diante da divisão digital, ou então, podemos inferir que estes movimentos já se apropriaram indiretamente desta divisão, ao se rebelarem contra diversas formas de injustiças do planeta.

As "comunidades instantâneas" de Castells (2013) apresentadas aqui podem favorecer a constituição do comum, comunidade tecida no compartilhamento, na aceitação das diferenças, das singularidades e potencializar as vozes dos integrantes dos movimentos sociais, das maiorias populares, rompendo a separação entre aqueles que estão no centro e os que residem nas periferias. Ao contrário do que vimos nas comunidades instantâneas de Castells (2013), as comunidades instantâneas de Bauman (2003) encontram-se prontas para o consumo imediato, são descartáveis depois de usadas e fazem parte da indústria do entretenimento.

Podemos, ainda, considerar que estas comunidades instantâneas de Castells (2013), ao possibilitarem a construção de relações humanas distantes da lógica hierárquica e identitária, inauguram, no bojo do contexto globalizado, formas híbridas de estar no mundo.

\section{Considerações Finais}

Fizemos um recorte sobre o conceito de comunidade, estabelecendo algumas correlações com o campo da psicologia comunitária. Não esgotamos este assunto e pretendemos continuar nossa pesquisa em outros estudos. Defendemos neste artigo uma visão histórica e política sobre este conceito. Estamos inclinados a afirmar que esta problematização possibilita uma visão que aspira à constituição do comum e à produção de redes associativas, no encontro das singularidades na contemporaneidade. Esta afirmação é contrária a uma crescente individualização e homogeneização dos nossos tempos.

Considerando todas as contradições do processo histórico na construção do contexto moderno, a concepção de comunidade se apropria de formas de resistência ao modo de vida industrial. $\mathrm{Na}$ contemporaneidade, seguimos atentos aos movimentos que rechaçam formas opressivas de laços comunitários. Na indústria de entretenimento e na sociedade de consumo não há lugar para o compartilhamento e para aceitação das diferenças.

A leitura e o engajamento dos psicólogos nas lutas sociais e na dinâmica societária têm apontado avanços consideráveis na psicologia, como ciência e profissão. Por este motivo, sustentamos um aprofundamento sobre o conceito de comunidade, visando sua desnaturalização, pois vimos que não há uma essência comunitária 
universal. Homogeneizar a comunidade promove uma distância cada vez maior entre aqueles que estão no centro e os que tentam a sobrevivência na periferia.

Em tempos de retrocessos, faz-se mister examinar os anos 1970, quando o conceito de comunidade surge como referencial de análise na psicologia social comunitária. O rompimento com o enfoque adaptativo da psicologia social norte-americana possibilitou outra visão que, conforme analisam Ximenes, Cidade, Nepomuceno e Leite (2014), a de uma psicologia comunitária que aspira atender às demandas e potencialidades dos sujeitos inseridos em uma conjuntura social. Esta apresenta uma concepção de um campo psicológico capaz de perceber a realidade criticamente, buscar a integração entre teoria, prática e compromisso com a transformação social e a consequente afirmação de uma práxis da comunidade, práxis do comum, que se faz com o encontro entre as diferenças.

Em tempos sombrios, na política pública ou em outros espaços organizacionais, entendemos que seja fundamental não perder de vista os princípios do SUS, de humanização dos serviços e de respeito às diversidades das experiências dos cidadãos e cidadãs.

Vimos que as redes de indignação presentes nos movimentos sociais na era da internet, as "comunidades instantâneas", chamadas assim por Castells (2013), são híbridas e heterogêneas. O que importa é a mobilização, a aposta na proximidade para tentarmos vencer o medo, que é superado pelo entusiasmo, pela ação comunicativa do coletivo. A este híbrido de cibernética e espaço urbano, Castells dá o nome de espaço da autonomia, uma força transformadora, desafiando a ordem institucional disciplinar, possibilitando reclamar o espaço da cidade para seus cidadãos.

Tomando as práticas comunitárias na perspectiva da psicologia social comunitária, rompemos a perspectiva sociológica disciplinar do conceito de comunidade, acolhemos as forças micropolíticas das maiorias populares, apostamos na criação de práticas e estamos abertos a um exame constante destes novos fazeres em direção a uma perspectiva ética e política.

\section{Referências}

Afonso, M. L. M., Vieira-Silva, M., Abade, F. L., Abrantes, T. M., \& Fadul, F. M. (2012). A Psicologia no Sistema Único de Assistência Social. Revista Pesquisa e Práticas Psicossociais, 7(2). 189-199. Retirado de https://ufsj.edu.br/portal2repositorio/File/revistalapip/Volume7_n2/Afonso,_Maria_Lucia_ Miranda,_et_al.pdf 
Andery, A. A. (1992). Psicologia na comunidade. In S. T. M. Lane \& W Codo, Psicologia Social: O Homem em Movimento (pp. 203220). São Paulo: Brasiliense.

Ansara, S., \& Dantas, B. A. M. S. (2010). Intervenções Psicossociais na comunidade: desafios e práticas. Revista Psicologia \& Sociedade, 22(1), 95-103.

Bauman, Z. (2003). Comunidade: A busca por segurança no mundo atual. Rio de J aneiro: Zahar.

Castells. M. (2003). Galáxia da Internet: Reflexões sobre a Internet, os negócios e a Sociedade. Rio de Janeiro: Zahar.

Castells. M. (2013). Redes de Indignação e Esperança: Movimentos Sociais na era da Internet. Rio de Janeiro: Ed. Zahar.

Costa Araújo, R. (1999). O Processo de Inserção em Psicologia Comunitária: Ultrapassando o nível dos papéis. In I. Rocha Brandão \& Z. A. Cruz Bonfim (Orgs.), Os Jardins da Psicologia Comunitária: Escritos sobre a Trajetória de um Modelo Teórico Vivencial (pp. 79-96). Fortaleza: UFC / ABRAPSO.

Domingues, A. R., \& Franco, E. M. (2014). Reflexões teóricas sobre sujeitos coletivos e experiências comunitárias. In C. Stella, Psicologia Comunitária: Contribuições teóricas, encontros e experiências (pp. 15-44). Rio de Janeiro: Vozes.

Freitas, M. F. Q. (1996). Contribuições da Psicologia Social e Psicologia Política ao desenvolvimento da Psicologia Social Comunitária. Psicologia e Sociedade, 8(1), 63-82. São Paulo: ABRAPSO.

Freitas, M. F. Q. (1999). Psicologia na Comunidade, Psicologia da Comunidade e Psicologia (Social) Comunitária: Práticas da psicologia em comunidade nas décadas de 60 a 90, no Brasil. In R. H. F. Campos (Org.), Psicologia Social Comunitária: Da solidariedade à autonomia (pp. 54-80). Rio de Janeiro: Vozes.

Freitas, M. F. Q. (2014). Psicologia Social Comunitária como politização da vida cotidiana: desafios à prática em comunidade. In C. Stella, (Org.), Psicologia Comunitária: Contribuições teóricas, encontros e experiências (pp. 65-85). Rio de Janeiro: Vozes.

Garcia, J., Morgado, R., \& Vasconcelos, E. (2011). O psicólogo e sua inserção no SUAS: Da sensação inicial de perda de identidade ao reconhecimento de uma nova profissionalidade e de suas bases teóricas. In Cadernos de Assistência Social: contribuições para a proteção básica e proteção especial (Vol 1, pp. 1-29). Resende, RJ: Secretaria Municipal de Assistência Social e Direitos Humanos.

Gavroglu, K., Patinotis, M., Papanelopoulou, F., Simões, A., Carneiro, A., Diogo, M. P., Sánchez, J. R. B., Belmar, A. G. \& Nieto-Galan, A. (2008). Science and Techonology in the European Periphery: 
Some Historiographical Reflections. History of Science, 46(2), 153-175.

Góis, C. W. L. (2005). Psicologia Comunitária: Atividade e consciência. Fortaleza: Instituto Paulo Freire.

Lane, S. T. M. (1992). Psicologia Social: O homem em movimento. São Paulo: Brasiliense.

Martin-Baró, I. (2017). Crítica e Libertação na Psicologia: Estudos psicossociais ( $F$. Lacerda Júnior, Trad.). Rio de Janeiro: Vozes.

Nascimento, M. L. (2001). História do trabalho comunitário em Psicologia. In A. M. Jacó Vilela, A. C. Cerezzo \& H. B. C. Rodrigues (Orgs), Clio-Psyché hoje: Fazeres e dizeres psi na história do Brasil (pp. 41-48). Rio de Janeiro: Relumè Dumará, Faperj.

Oberg, L. P. (2008). Do rio das vitrines à galeria dos desconhecidos: Um estudo em Psicologia Social Comunitária na Localidade de Muzema. São Paulo: Biblioteca 24X7.

Oberg, L. P. (2015). Esqueça a Casa e o Trabalho/a vida fica lá fora: Reflexões de uma prática Comunitária. Polêmica, 14, 113-128. Retirado de http://www.epublicacoes.uerj.br/index. php/polemica/article/view/14271/108 00

Oliveira, I. F. (2014). Os desafios e limites para a atuação do psicólogo no SUAS. In L. R. Cruz \& N. Guareschi (Orgs), O psicólogo e as políticas públicas de assistência social (pp. 3551). Rio de Janeiro: Ed. Vozes.

Palácios, M. (2001). O medo do vazio: Comunicação, sociabilidade e novas tribos. In A. A. Rubin (Org), Idade mídia. Salvador: UFBA.

Rocha, T. G., \& Kastrup, V. (2008). Partilha do sensível na comunidade: Intersepsicologia e teatro. Estudos de Psicologia (Natal), 13(2), 97-105.

Sawaia, B. (1999). Comunidade: A apropriação científica de um conceito tão antigo quanto a teatro. Estudos de Psicologia (Natal), 13(2), 97-105.

Sawaia, B. (1999a). As Artimanhas da exclusão: Análise psicossocial e ética da desigualdade social. Petrópolis, Rio de Janeiro: Vozes.

Scarparo, H., \& Guareschi, N. (2007). Psicologia social comunitária e formação profissional. Revista Psicologia \& Sociedade, 19(ed. Especial 2), 100-108. Retirado de http: //www.redalyc. org/articulo.oa?id=309326391024. ISSN $0102-7182$

Simmel, G. (1979). A Metrópole e a vida mental. In G. O. Velho, Fenômeno Urbano (pp. 11-25). Rio de Janeiro: Zahar. 
Soares, A. B. (2001). Comunidades e intervenções. Olhares em (Des)construção. (Dissertação de Mestrado). Universidade do Estado do Rio de Janeiro, Rio de Janeiro.

Tönnies, F. (1955). Community and Association London. In M. Buber (1987), Sobre Comunidade (C. P. Loomis, Trad.). São Paulo: Perspectiva.

Weber, M. (1973). Comunidade e sociedade como estruturas de socialização. In F. Florestan (Org.) (2003), Comunidade e sociedade: Leituras sobre problemas conceituais, metodológicos e de aplicação (pp. 140-143). São Paulo: Editora da USP.

Ximenes, V. M., Cidade, E. C., Nepomuceno, B. B. \& Leite, J. F. (2014). Pesquisa e intervenção a partir da realidade social: Desvelar das implicações psicossociais da pobreza. In C. Stella (Org.), Psicologia Comunitária. Contribuições teóricas, encontros e experiências (pp. 87-110). Rio de Janeiro: Vozes.

Zamora, M. H. (1999). Textura áspera: Confinamento, sociabilidade e violência em favelas carioca (Tese de Doutorado em Psicologia Clínica). Pontifícia Universidade Católica Rio, Rio de Janeiro.

Zamora, M. H. (2004). Raízes e Asas da Psicologia Comunitária. In J. Vilhena (Org.), A Clínica na Universidade: Teoria e Prática (pp. 123-124). Rio de Janeiro: PUC-Rio, Loyola.

\section{Endereço para correspondência Lurdes Perez Oberg}

Universidade Federal Fluminense - UFF

Rua Visconde Caravelas, 41/303, Botafogo, CEP 22271-021, Niterói - RJ, Brasil

Endereço eletrônico: lurdes.oberg@gmail.com

Recebido em: 24/08/2015

Reformulado em: 09/09/2017

Aceito em: 09/09/2017

\section{Notas}

* Doutorado em Psicologia (Psicologia Clínica) pela Pontifícia Universidade Católica do Rio de Janeiro (2007). Atualmente é professora adjunta e supervisora de estágio em Práticas comunitárias em localidades rurais da Universidade Federal Fluminense, em Campos dos Goytacazes.

Este artigo de revista Estudos e Pesquisas em Psicologia é licenciado sob uma Licença Creative Commons Atribuição-Não Comercial 3.0 Não Adaptada. 